\title{
Interfacial Structures Governed Plastic Deformation Behaviors in Metallic Multilayers
}

\author{
Ming-Zhen Wei ${ }^{1,2} \cdot$ Zhen-Hua Cao $^{1} \cdot$ Xiang-Kang Meng ${ }^{1}$
}

Received: 25 November 2015/Revised: 8 January 2016/Published online: 8 February 2016

(C) The Chinese Society for Metals and Springer-Verlag Berlin Heidelberg 2016

\begin{abstract}
In this work, we have investigated the mechanical properties of $\mathrm{Cu} / \mathrm{Ta}, \mathrm{Ag} / \mathrm{Cu}$ and $\mathrm{Ag} / \mathrm{Nb}$ multilayers with different heterogeneous interfaces. The results suggest that when individual layer thickness $(h)$ is larger than 5-10 $\mathrm{nm}$, the hardness/strength of three different multilayer systems has the similar length scale effect with decreasing layer thickness, while when $h \leq 5 \mathrm{~nm}$, the three multilayer systems show remarkably different plastic deformation behaviors. The strength curves exhibit the variation trends of unchanging, softening and increasing corresponding to $\mathrm{Cu} / \mathrm{Ta}, \mathrm{Ag} / \mathrm{Cu}$ and $\mathrm{Ag} / \mathrm{Nb}$ multilayers, respectively. The microstructure analysis shows that three kinds of multilayers have totally different interfacial structures, which lead to the different strengthening or softening mechanisms.
\end{abstract}

KEY WORDS: Metallic multilayers; Plastic deformation; Interfacial structures; Strengthening mechanism

\section{Introduction}

Metallic multilayer films have attracted much attention due to their outstanding mechanical properties [1-4]. The yield strengths of some multilayers can even approach $1 / 3-1 / 2$ of the theoretical strength limit $[5,6]$. The strengthening mechanisms of multilayers have been investigated extensively, and three typical mechanisms have been developed to interpret the plastic deformation behaviors in multilayers. Hall-Petch (H-P) model based on pilling-up of dislocations against the interface or grain boundaries is applicable when the individual layer thickness $(h)$ is more

Available online at http://link.springer.com/journal/40195

Zhen-Hua Cao

caozhenhua@nju.edu.cn

1 Institute of Materials Engineering, National Laboratory of Solid State Microstructures, College of Engineering and Applied Sciences, Nanjing University, Nanjing 210093, China

2 Department of Physics, School of Science, Linyi University, Linyi 276000, China than tens of nanometers [7-9]. At smaller $h$ of a few to tens of nanometers, the confined layer slip (CLS) mechanism involving the single dislocation loops gliding in both layers dominants the plastic deformation [10-12]. When $h$ decreases to several nanometers, the strengthening is mainly ascribed to the interface barrier strength (IBS) to the transmission of a single dislocation [13-15].

The heterogeneous interfaces between layers play a key role in the strengthening of multilayers [16-18]. Different types of interfaces provide different barrier effects to the transmission of deformation. The interfaces can be classified as coherent, semi-coherent and incoherent, depending on the lattice parameters of the constituents of multilayer systems [19-21]. Many studies in multilayers, such as $\mathrm{Cu} /$ $\mathrm{V}$ [22], $\mathrm{Co} / \mathrm{Cu}$ [23], $\mathrm{Cu} / \mathrm{Ni}[3,24], \mathrm{Cu} / \mathrm{Zr}$ [25, 26], $\mathrm{Cu} / \mathrm{Nb}$ [27] and $\mathrm{Cu} / \mathrm{Fe}$ [28] multilayers, have shown that the strength of multilayers increases with decreasing layer thickness and reaches plateau when $h$ decreases to several nanometers. However, with further investigation, the contradictory plastic deformations have been reported when $h$ is lower than $5 \mathrm{~nm}$. Some metallic multilayers show a continuous strengthening even when $h$ decreases to $1-2 \mathrm{~nm}$ $[29,30]$, while in other multilayers the softening occurs at 
$\sim 5 \mathrm{~nm}$. These different plastic deformation behaviors are closely related to the interfacial structures and the interaction between interfaces and partial dislocations. Hence, it is significant to investigate the interfacial structures and how the different interfaces acting as barriers to dislocation glide, which is helpful to achieve the optimum selection of multilayer systems.

In the present work, three different multilayer systems $\mathrm{Cu} / \mathrm{Ta}, \mathrm{Ag} / \mathrm{Cu}$ and $\mathrm{Ag} / \mathrm{Nb}$ have been chosen to investigate the relationship between strengthening and the interfacial structures. Three typical crystal lattices, including facecentered cubic (fcc), body-centered cubic (bcc) and tetragonal (tet) structures, are employed. $\mathrm{Cu} / \mathrm{Ta}, \mathrm{Ag} / \mathrm{Cu}$ and $\mathrm{Ag} / \mathrm{Nb}$ multilayers are the composite systems of fcc/tet, $\mathrm{fcc} / \mathrm{fcc}$ and fcc/bcc, respectively. A comparison of the systems studied is shown in Table 1 . In our previous work, we have reported the ultrahigh strengthening behavior in $\mathrm{Ag} / \mathrm{Nb}$ multilayers [30] and the abnormal softening behavior in $\mathrm{Cu} / \mathrm{Ta}$ multilayers $[4,31]$. However, the further researches are still needed on how the characteristics of interfaces, including the crystallinity, the structural discontinuity and crystal orientation between layers, affect the mechanical properties of multilayers. Here we systematically studied the heterogeneous interface governed plastic deformation behaviors of metallic multilayers.

\section{Experimental}

$\mathrm{Cu} / \mathrm{Ta}, \mathrm{Ag} / \mathrm{Cu}$ and $\mathrm{Ag} / \mathrm{Nb}$ multilayers were deposited on $\mathrm{Si}$ substrates at room temperature by dc magnetron sputtering. The individual layer thickness ranged from 1 to $50 \mathrm{~nm}$ for each multilayer system, and both of constituent layers were equal with each other. Base pressure for the sputtering chamber was kept at less than $9 \times 10^{-5} \mathrm{~Pa}$, and the sputtering pressure was 1.2 Pa. Total thickness of the multilayers was $1000 \mathrm{~nm}$. For comparison, the pure $\mathrm{Cu}, \mathrm{Ta}, \mathrm{Ag}$ and $\mathrm{Nb}$ thin films with the thickness of $1000 \mathrm{~nm}$ were prepared under the same circumstances.

The cross-sectional microstructures were characterized by using a JEOL JEM-2100 transmission electron microscope (TEM) with $200-\mathrm{kV}$ accelerating voltages. The nanoindentation tests were performed using a TI950

Table 1 Comparison of three different multilayer systems

\begin{tabular}{llll}
\hline Multilayers & Crystal lattice & Interface misfit $(\%)^{\mathrm{a}}$ & Interface type \\
\hline $\mathrm{Cu} / \mathrm{Ta}$ & fcc/tet & - & Incoherent \\
$\mathrm{Ag} / \mathrm{Cu}$ & $\mathrm{fcc} / \mathrm{fcc}$ & 12 & Semi-coherent \\
$\mathrm{Ag} / \mathrm{Nb}$ & $\mathrm{fcc} / \mathrm{bcc}$ & 1 & Coherent
\end{tabular}

${ }^{a}$ Interface misfit indicates the misfit of interplanar spacing between close-packed planes, i.e., $\operatorname{Ag}(111)$ and $\mathrm{Cu}(111)$ for fcc/fcc, $\operatorname{Ag}(111)$ and $\mathrm{Nb}(110)$ for fcc/bcc, respectively
Hysitron Triboindenter with a displacement resolution of $0.1 \mathrm{~nm}$ and a loading resolution of $50 \mathrm{nN}$. A Berkovich tip with $50 \mathrm{~nm}$ radius of curvature was used in all indentation experiments. The maximum indentation depth was controlled at $150 \mathrm{~nm}$ (about $15 \%$ of the multilayer thickness) to minimize the effects of substrate, and the same ramp rate $\dot{P} / P=0.1 \mathrm{~s}^{-1}$ was adopted when the nanoindentation tests of $\mathrm{Cu} / \mathrm{Ta}, \mathrm{Ag} / \mathrm{Cu}$ and $\mathrm{Ag} / \mathrm{Nb}$ multilayers were performed.

\section{Results and Discussion}

The typical load-displacement curves of $\mathrm{Cu} / \mathrm{Ta}, \mathrm{Ag} / \mathrm{Cu}$ and $\mathrm{Ag} / \mathrm{Nb}$ multilayers with $h=5 \mathrm{~nm}$ are shown in Fig. 1 . These curves reflect the differences in hardness of the three types of multilayers. At the same maximum indentation depth of $150 \mathrm{~nm}$, the higher load means the higher hardness. From Fig. 1, we can conclude that the hardness of $\mathrm{Cu} /$ Ta multilayer is the highest while that of $\mathrm{Ag} / \mathrm{Cu}$ multilayer is the lowest when $h=5 \mathrm{~nm}$. All the hardness plotted as a function of $h$ of $\mathrm{Cu} / \mathrm{Ta}, \mathrm{Ag} / \mathrm{Cu}$ and $\mathrm{Ag} / \mathrm{Nb}$ multilayers with $h$ in the range of $1-100 \mathrm{~nm}(3-100 \mathrm{~nm}$ for $\mathrm{Ag} / \mathrm{Cu})$ is shown in Fig. 2a. Meanwhile, in order to explore the strengthening mechanisms of the multilayers and observe the variation trends more clearly when $h \leq 5 \mathrm{~nm}$, the strength plotted as a function of $h^{-1 / 2}$ is shown in Fig. $2 \mathrm{~b}$. The strength is estimated as indentation hardness divided by a factor of 2.7 [32]. It can be seen that the hardness/ strength of three multilayer systems changes with decreasing $h$ and shows different length scale effects. The strength of $\mathrm{Cu} / \mathrm{Ta}$ multilayers increases with $h$ and reaches a peak at $h=10 \mathrm{~nm}$. A sharp decrease can be obviously observed when $h$ is in the range of 5-10 nm. It comes from the phase transformation in Ta layers, which has been reported in our previous work [31]. The strength in $\mathrm{Ag} / \mathrm{Cu}$

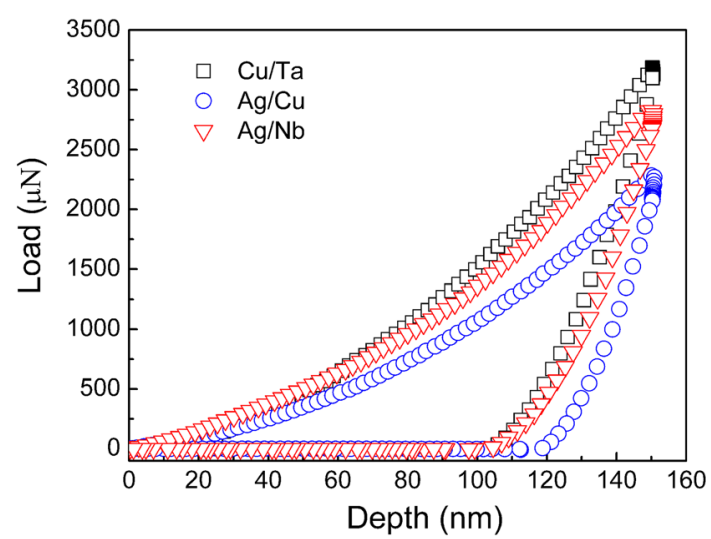

Fig. 1 Typical load-displacement curves of $\mathrm{Cu} / \mathrm{Ta}, \mathrm{Ag} / \mathrm{Cu}$ and $\mathrm{Ag} /$ $\mathrm{Nb}$ multilayers with $h=5 \mathrm{~nm}$ 

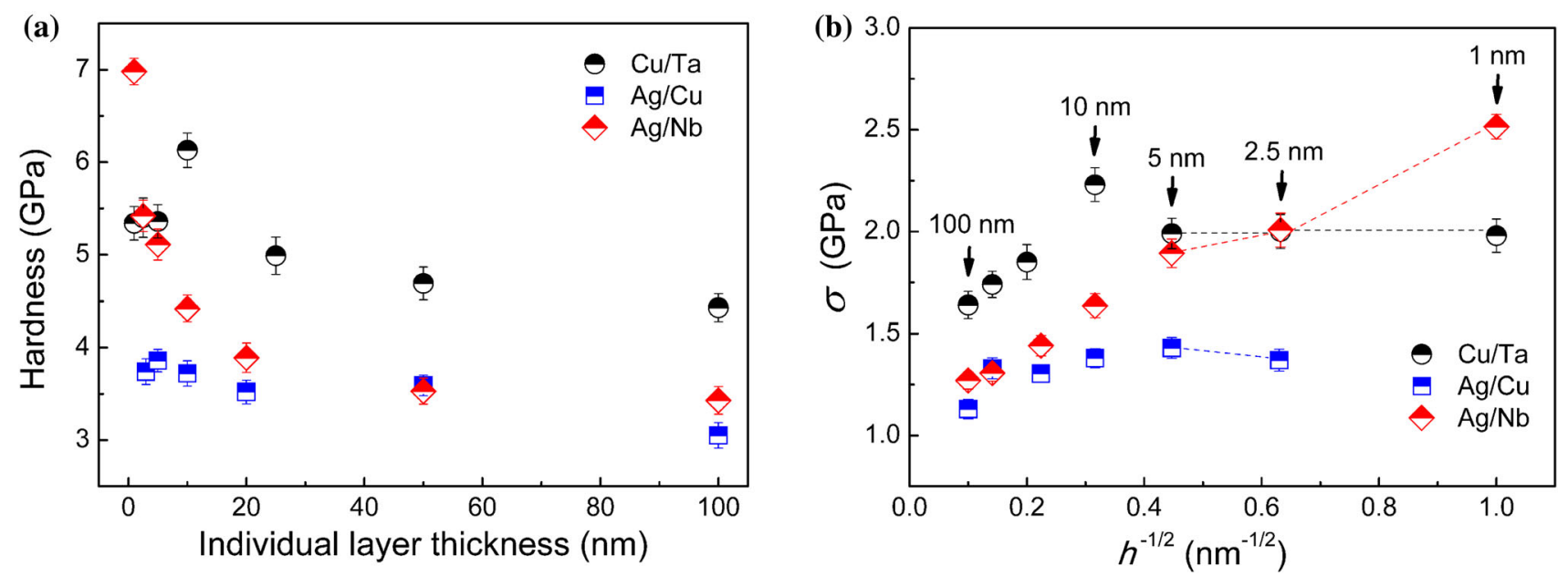

Fig. 2 a Hardness of $\mathrm{Cu} / \mathrm{Ta}, \mathrm{Ag} / \mathrm{Cu}$ and $\mathrm{Ag} / \mathrm{Nb}$ multilayers plotted as a function of $h$; $\mathbf{b}$ strength plotted as a function of $h^{-1 / 2}$

multilayers increases with decreasing $h$ in the range of 5-100 $\mathrm{nm}$ and softens at $h<5 \mathrm{~nm}$, while in $\mathrm{Ag} / \mathrm{Nb}$ multilayers, the strength increases with decreasing $h$ and shows a sharply rising trend even when $h$ decreases to $1 \mathrm{~nm}$. By comparing three different strength curves, we find that the differences mainly exist in the range of $1-5 \mathrm{~nm}$. When $h$ is larger than 5-10 nm, the trends are similar except that the strength of $\mathrm{Ag} / \mathrm{Cu}$ multilayer with $h=50 \mathrm{~nm}$ is higher than that with $h=20 \mathrm{~nm}$, which has been explained in the Ref. [33]. When $h \leq 5 \mathrm{~nm}$, the three strength curves have the different variation trends of unchanging, softening and increasing corresponding to $\mathrm{Cu} / \mathrm{Ta}, \mathrm{Ag} / \mathrm{Cu}$ and $\mathrm{Ag} / \mathrm{Nb}$ multilayers, respectively.

In order to clearly reveal the effect of the interfacial structures on the mechanical properties, we investigated the cross-sectional microstructures of three different multilayers with $h=5 \mathrm{~nm}$. Figure 3 gives the cross-sectional TEM and high-resolution TEM (HRTEM) images of $\mathrm{Cu} / \mathrm{Ta}$ multilayers with $h=5 \mathrm{~nm}$, respectively. From
Fig. 3a, it can be seen that an alternative lamellar structure is clearly visible and the interface is sharp and straight. No obvious columnar grains can be observed. From the HRTEM image of Fig. 3b, the lattice fringes can be seen in $\mathrm{Cu}$ layers, indicating the $\mathrm{Cu}$ grains well crystallite. The fringes in Ta layers are slightly random which indicates the crystallinity is weak and only tiny nanograins form. In our previous works [4, 31], we have reported that the tetragonal $\beta$-Ta and cubic $\alpha$-Ta coexist in Ta layers when $h>5 \mathrm{~nm}$, while only $\alpha$-Ta forms when $h \leq 5 \mathrm{~nm}$, which may be the reason why the hardness/ strength drops sharply with decreasing $h$ from 10 to $5 \mathrm{~nm}$. In fact, the crystal $\alpha$-Ta forms at some special sites with straight interface and generates exactly on the neat $\mathrm{Cu}(111)$ plane [31]. The selected area electron diffraction (SAED) pattern of the $\mathrm{Cu} / \mathrm{Ta}$ multilayer with $h=5 \mathrm{~nm}$ is shown in the inset of Fig. 3a, and all of the diffraction rings can be identified as reflections from $\mathrm{Cu}$ phase and $\alpha$ Ta phase, respectively.
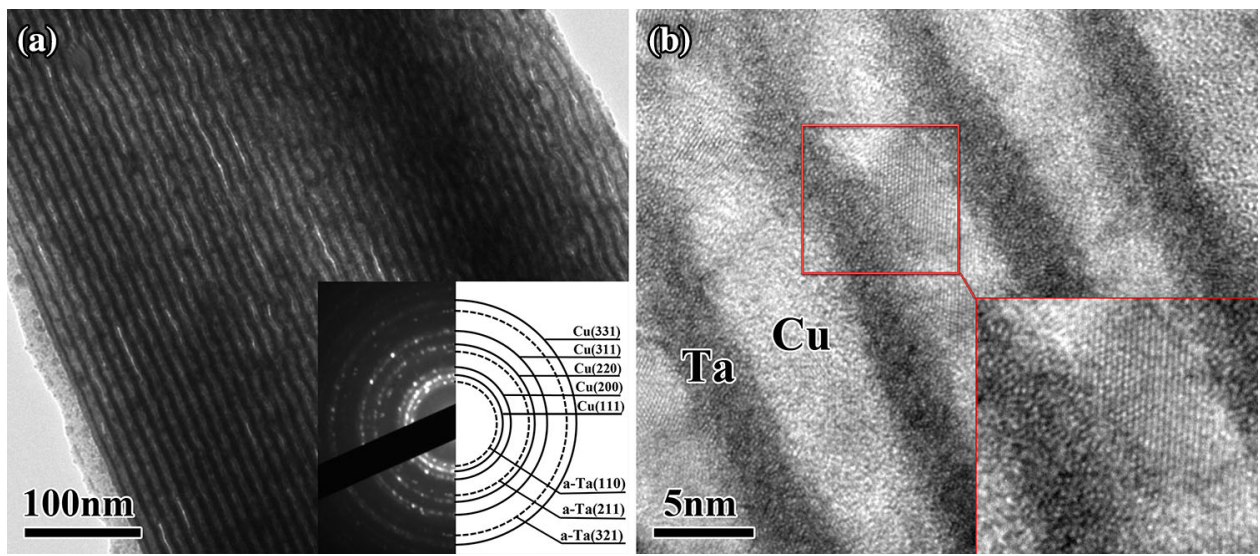

Fig. 3 Bright field cross-sectional TEM a and HRTEM b images of $\mathrm{Cu} / \mathrm{Ta}$ multilayer with $h=5 \mathrm{~nm}$ (the light gray layers indicate the $\mathrm{Cu}$ layers, and the dark gray layers indicate the Ta layers; the inset in a is the corresponding SAED pattern) 
Figure 4 presents the cross-sectional TEM and HRTEM images of $\mathrm{Ag} / \mathrm{Cu}$ multilayers with $h=5 \mathrm{~nm}$. They reveal the morphology of regular interface interrupted by the periodical defect regions to reduce the mismatch strain, exhibiting a typical semi-coherent interface. The width of column grains is larger than layer thickness. The interface is a little wavy, and the columns are successive along the growth direction of multilayer. The inset in Fig. $4 \mathrm{a}$ is the corresponding SAED pattern of the cross section with $h=5 \mathrm{~nm}$. The diffraction rings can be identified as reflections from $\mathrm{Ag}$ and $\mathrm{Cu}$ phases which can indicate the orientation relationship between $\mathrm{Ag}$ and $\mathrm{Cu}$. From HRTEM image of Fig. 4b, we can see that the consecutive atomic arrangement extends from $\mathrm{Ag}$ layer to $\mathrm{Cu}$ layer across the interface, suggesting the epitaxial relationship between them. It is confirmed that the multilayer has a strong orientation relationship of a cube-on-cube growth. Meanwhile, there are many stacking faults growth from Ag layer to $\mathrm{Cu}$ layer across the interface, which can improve the barrier strength of interfaces.

Figure 5 shows the cross-sectional TEM and HRTEM images of $\mathrm{Ag} / \mathrm{Nb}$ multilayer with $h=5 \mathrm{~nm}$. The lamellar structure can be easily identified. The interfaces are straighter than $\mathrm{Ag} / \mathrm{Cu}$ multilayers. The inset in Fig. 5a is the corresponding SAED pattern of $\mathrm{Ag} / \mathrm{Nb}$ multilayer with $h=5 \mathrm{~nm}$, which indicates the orientation relationship between $\mathrm{Ag}$ and $\mathrm{Nb}$. From the HRTEM image of Fig. 5b, we can see that the interfacial morphology is very different from what observed in $\mathrm{Cu} / \mathrm{Ta}$ and $\mathrm{Ag} / \mathrm{Cu}$ multilayers. The interfaces in $\mathrm{Ag} / \mathrm{Nb}$ system are more ordered than the above two, exhibiting a coherent interfacial structure. The parallel lattice fringes can be seen in both $\mathrm{Ag}$ and $\mathrm{Nb}$ layers, indicating that the grains in-plane have the strong textures. The values of the interplanar spacings in $\mathrm{Ag}(0.236 \mathrm{~nm})$ and $\mathrm{Nb}(0.234 \mathrm{~nm})$ layers are corresponding to $\mathrm{Ag}(111)$ and $\mathrm{Nb}$ (110) planes, respectively. Furthermore, the detailed atomic arrangement shows that $\mathrm{Ag}(111)$ and $\mathrm{Nb}(110)$ planes are continuous across the interface. The orientation relationship had been confirmed in our previous work [30] that two different orientations exist along the interfaces, a Kurdjumov-Sachs (K-S) relationship $(\mathrm{Ag}(111) / / \mathrm{Nb}(110), \mathrm{Ag}$ $<110>/ / \mathrm{Nb}<111>$ ) and a Nishiyama-Wasserman $(\mathrm{N}-\mathrm{W})$ relationship $(\mathrm{Ag}(111) / / \mathrm{Nb}(110), \mathrm{Ag}<112>/ / \mathrm{Nb}<110>)$. Furthermore, some misfit dislocations can be observed at the interfaces due to the lattice mismatch between $\mathrm{Ag}$ and $\mathrm{Cu}$ layers. The stacking faults also appear in Ag layers. They both contribute to the strength of multilayers.

From the comparison of above three multilayer systems, we find that the differences of length scale effect on the hardness/strength arise at the scale of lower than 5-10 nm. At larger scales, the strength of the three kinds of multilayers varies linearly with $h^{-1 / 2}$, and hence the strengthening can be interpreted by the H-P model [7]. Usually, when $h$ decreases to a few nanometers, a peak strength is typically reached (it can act as a characteristic scale, and in our experiments it is about $5 \mathrm{~nm}$ ). At this small length scale, the interface barrier to the transmission of a single dislocation plays the key role in the strengthening [13, 34]. The interface factor becomes vital, and strengthening relating to the interface should be considered, such as Koehler stress and coherency stress [11, 13, 14], which results from the shear modulus mismatch and lattice mismatch, respectively. In addition, Wang and Misra [35] proposed that the interface barriers are also correlated with the defect structure of the interface and the crystallographic orientation relationships. In $\mathrm{Cu} / \mathrm{Ta}$ multilayers, the crystallinity of Ta layers is weak, the interface between layers is incoherent, and coherent stress does not exist. Hence, the barrier of interface originates from Koehler stress due to great modulus mismatch. This is the reason that the strength of $\mathrm{Cu} / \mathrm{Ta}$ multilayers with $h \leq 5 \mathrm{~nm}$ is independent of the layer thickness.

In $\mathrm{Ag} / \mathrm{Cu}$ multilayers, a softening is observed when $h \leq 5 \mathrm{~nm}$. This softening is very similar to what has been reported in $\mathrm{Cu} / \mathrm{Ni}$ multilayers which results from the
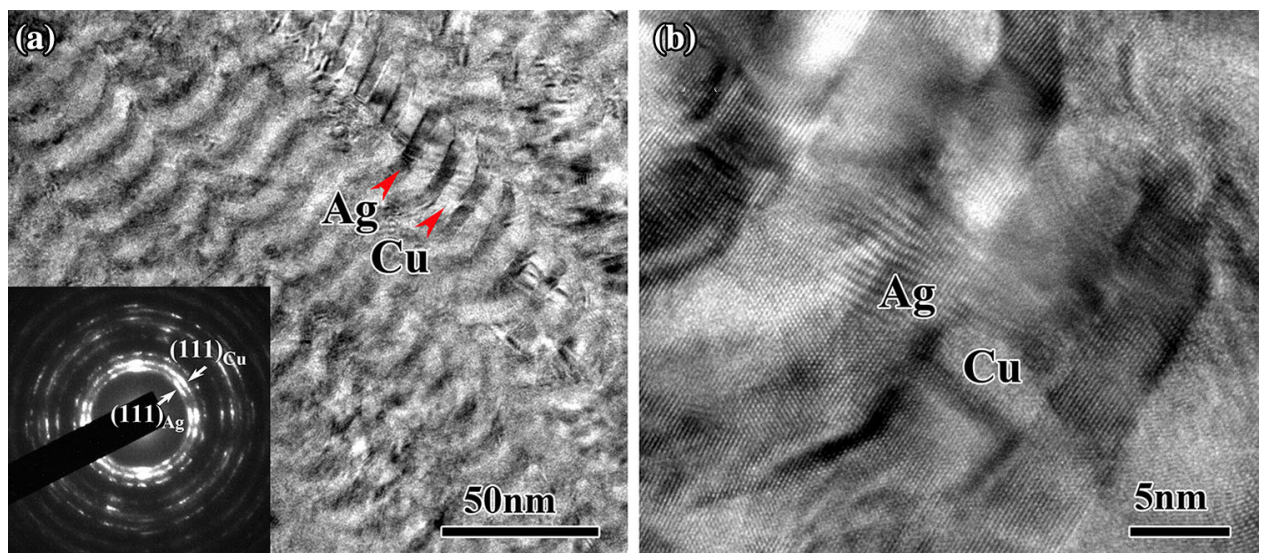

Fig. 4 Bright field cross-sectional TEM a and HRTEM $\mathbf{b}$ images of Ag/Cu multilayer with $h=5 \mathrm{~nm}$ (the inset in a is the corresponding SAED pattern) 

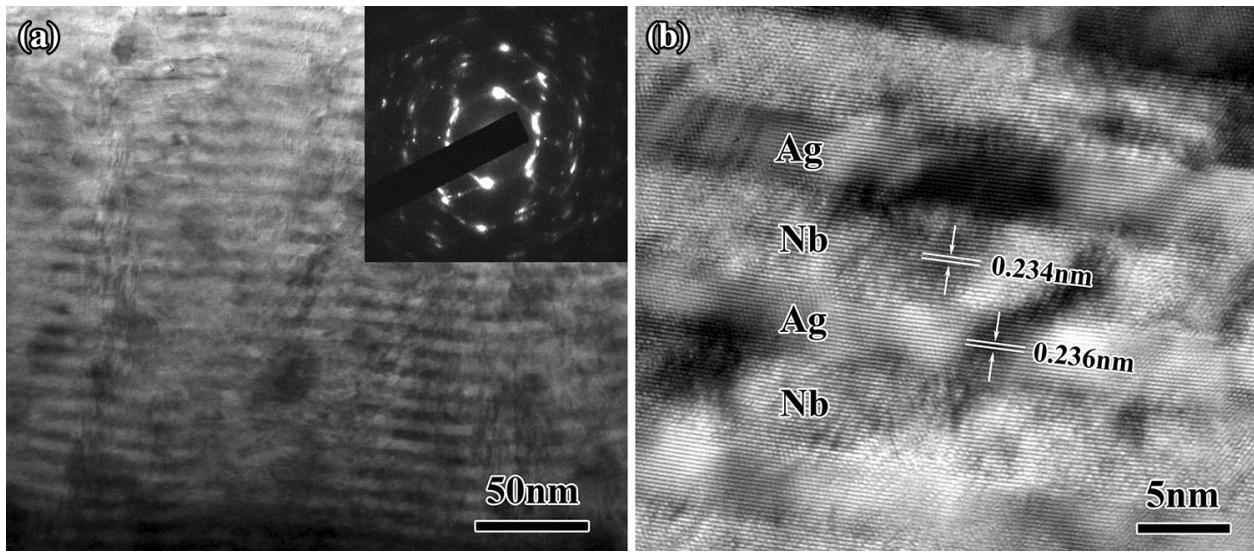

Fig. 5 Bright field cross-sectional TEM a and HRTEM b images of Ag/Nb multilayer with $h=5 \mathrm{~nm}$ (the light gray layers indicate the $\mathrm{Nb}$ layers, and the dark gray layers indicate the Ag layers; the inset in a is the corresponding SAED pattern)

superlattice structure [24]. In $\mathrm{Ag} / \mathrm{Cu}$ multilayers, the superlattice forms when $h$ is less than $5 \mathrm{~nm}$. Meanwhile, the $\mathrm{fcc} / \mathrm{fcc}$ crystal lattice system gives the interfaces transparent, i.e., the slip planes and slip directions of the adjacent layers are continuous. When a partial dislocation transmits from $\mathrm{Ag}$ to $\mathrm{Cu}$ layers, the interface poses a minor resistance to slip transmission, leading to a reduction of strength $[17,36]$. The superlattice structure is more pronounced with the less layer thickness. It is the reason why a softening occurs when $h$ falls from 5 to $3 \mathrm{~nm}$.

In $\mathrm{Ag} / \mathrm{Nb}$ multilayers, the different situations appear and the strength increases continuously until $h=1 \mathrm{~nm}$. From the comparison of the cross-sectional images, one can find the interfacial structure of $\mathrm{Ag} / \mathrm{Nb}$ multilayer is very different from that of the other two. The interface is coherent, and the hetero-epitaxial structures form due to the low lattice mismatch between $\mathrm{Ag}(111)$ and $\mathrm{Nb}(110)$ planes. At small length scale with $h \leq 5 \mathrm{~nm}$, the coherency stresses exist between $\mathrm{Ag}$ and $\mathrm{Nb}$ layers. The coherency stresses can inhibit partial dislocation motion, leading to the enhancement of strength. Furthermore, the structural difference (fcc/bcc) between $\mathrm{Ag}$ and $\mathrm{Nb}$ layers also produces a barrier to dislocation transmission across the interface due to the discontinuity of slip systems. When a dissociated glide dislocation slips from $\mathrm{Ag}$ layer to the opposite, dislocations pin near the interface and cannot directly penetrate the interface, which produces an additional applied stress [26, $34,36]$. In addition, the existence of stacking faults and misfit dislocations also contributes to the enhancement of multilayers, leading to a sustainable increase in strength.

\section{Conclusion}

It is found that the interfacial structure has a significant influence on the mechanical properties of multilayer systems. Three different plastic deformation behaviors have been obtained at small length scales. In $\mathrm{Ag} / \mathrm{Nb}$ multilayers, the strength is enhanced even when $h$ falls to $1 \mathrm{~nm}$. This high strengthening may result from the coherency stress, stacking faults and misfit dislocations. In $\mathrm{Ag} / \mathrm{Cu}$ multilayers, a softening occurs when $h<5 \mathrm{~nm}$, which is because of the formation of superlattice and the transparent interface of fcc/fcc structure, while in $\mathrm{Cu} / \mathrm{Ta}$ multilayers, the barrier strength of the interface is independent of the scales, leading to the stable strength when $h \leq 5 \mathrm{~nm}$.

Acknowledgments This work was financially supported by the PAPD (No. 50831004), the Fundamental Research Funds for the Central Universities, the Innovation Fund of Jiangsu Province (No. BY2013072-06), the Natural Science Foundation of Jiangsu Province (No. 20141234), the National Natural Science Foundation of China (Nos. 51171078 and 51371096), and the State Key Program for Basic Research of China (No. 2010CB631004).

\section{References}

[1] S.L. Lehoczky, J. Appl. Phys. 49, 5479 (1978)

[2] W.M.C. Yang, T. Tsakalakos, J.E. Hilliard, J. Appl. Phys. 48, 876 (1977)

[3] A. Misra, M. Verdier, Y.C. Lu, H. Kung, T.E. Mitchell, M. Nastasi, J.D. Embury, Scr. Mater. 39, 555 (1998)

[4] M.Z. Wei, Z.H. Cao, J. Shi, G.J. Pan, L.J. Xu, X.K. Meng, Mater. Sci. Eng. A 598, 355 (2014)

[5] B.M. Clemens, H. Kung, S.A. Barnett, MRS Bull. 24, 20 (1999)

[6] G.S. Was, T. Foecke, Thin Solid Films 286, 1 (1996)

[7] E.O. Hall, Proc. Phys. Soc. Lond. B 64, 747 (1951)

[8] N.J. Petch, J. Iron Steel Inst. 174, 25 (1953)

[9] P.M. Anderson, C. Li, Nanostruct. Mater. 5, 349 (1995)

[10] L.H. Friedman, D.C. Chrzan, Phys. Rev. Lett. 81, 2715 (1998)

[11] J.D. Embury, J.P. Hirth, Acta Metall. Mater. 42, 2051 (1994)

[12] M.A. Phillips, B.M. Clemens, W.D. Nix, Acta Mater. 51, 3157 (2003)

[13] J.S. Koehler, Phys. Rev. B 2, 547 (1970)

[14] A. Misra, J.P. Hirth, H. Kung, Philos. Mag. A 82, 2935 (2002)

[15] S.I. Rao, P.M. Hazzledine, Philos. Mag. A 80, 2011 (2000)

[16] R.C. Cammarata, K. Sieradzki, F. Spaepen, J. Appl. Phys. 87, $1227(2000)$ 
[17] R.G. Hoagland, R.J. Kurtz, C.H. Henager, Scr. Mater. 50, 775 (2004)

[18] Y.P. Li, G.P. Zhang, W. Wang, J. Tan, S.J. Zhu, Scr. Mater. 57, 117 (2007)

[19] J.A. Bain, L.J. Chyung, S. Brennan, B.M. Clemens, Phys. Rev. B 44, 1184 (1991)

[20] B. Shoykhet, M.A. Grinfeld, P.M. Hazzledine, Acta Mater. 46, 3761 (1998)

[21] F. Appel, U. Christoph, Intermetallics 7, 1173 (1999)

[22] E.G. Fu, N. Li, A. Misra, R.G. Hoagland, H. Wang, X. Zhang, Mater. Sci. Eng. A 493, 283 (2008)

[23] A. Tokarz, P. Wieczorek, T. Frączek, Z. Nitkiewicz, Phys. Status Solidi 5, 3526 (2008)

[24] Y. Liu, D. Bufford, H. Wang, C. Sun, X. Zhang, Acta Mater. 59, $1924(2011)$

[25] J.Y. Zhang, X. Zhang, G. Liu, G.J. Zhang, J. Sun, Mater. Sci. Eng. A 528, 2982 (2011)

[26] J.Y. Zhang, Y. Liu, J. Chen, Y. Chen, G. Liu, X. Zhang, J. Sun, Mater. Sci. Eng. A 552, 392 (2012)
[27] X.Y. Zhu, J.T. Luo, F. Zeng, F. Pan, Thin Solid Films 520, 818 (2011)

[28] Y. Chen, Y. Liu, C. Sun, K.Y. Yu, M. Song, H. Wang, X. Zhang, Acta Mater. 60, 6312 (2012)

[29] D. Bufford, Z. Bi, Q.X. Jia, H. Wang, X. Zhang, Appl. Phys. Lett. 101, 223112 (2012)

[30] M.Z. Wei, J. Shi, Y.J. Ma, Z.H. Cao, X.K. Meng, Mater. Sci. Eng. A 651, 155 (2016)

[31] M.Z. Wei, Z.H. Cao, J. Shi, G.J. Pan, L.J. Xu, X.K. Meng, Mater. Sci. Eng. A 646, 163 (2015)

[32] M. Mata, M. Anglada, J. Alcala, J. Mater. Res. 17, 964 (2002)

[33] M.Z. Wei, L.J. Xu, J. Shi, G.J. Pan, Z.H. Cao, X.K. Meng, Appl. Phys. Lett. 106, 011604 (2015)

[34] J.W. Yan, G.P. Zhang, X.F. Zhu, H.S. Liu, C. Yan, Philos. Mag. 93, 434 (2013)

[35] J. Wang, A. Misra, Curr. Opin. Solid State Mater. Sci. 15, 20 (2011)

[36] G.P. Zhang, X.F. Zhu, Acta Metall. Sin. 50, 148 (2014). (in Chinese) 